2016-02-04

\title{
Energy sustainability in operations: an optimization study
}

\author{
Shibin, KT
}

http://hdl.handle.net/10026.1/5546

10.1007/s00170-016-8398-6

The International Journal of Advanced Manufacturing Technology

Springer Science and Business Media LLC

All content in PEARL is protected by copyright law. Author manuscripts are made available in accordance with publisher policies. Please cite only the published version using the details provided on the item record or document. In the absence of an open licence (e.g. Creative Commons), permissions for further reuse of content should be sought from the publisher or author. 


\title{
Energy sustainability in Operations: An Optimization Study
}

\begin{abstract}
In recent years energy sustainability has attracted increasing attention from scholars, policy makers and practitioners. However, in practical competitiveness, companies also have to maintain flexibility to deliver customer requirements. Existing theory has largely seen flexibility and sustainability as separate issues, ignoring their relationship. To address this gap, we attempt to explore energy sustainability using flexible operations management practices in India. Following a case research methodology, we investigate how flexible operations management practices embraced by a leading organization that minimizes energy consumption in plants with better resource utilization and better quality of work life for staff to meet the future requirements based on market forecast. We solve a real time multi-criteria strategic capacity planning problem with multiple objectives such as throughput maximization, waste minimization and resource utilization maximization by using discrete event simulation technique. Our data stems from ongoing research within a car manufacturing company in India, located at Pune. Shift timings, setup time, production batch size and differential rated capacities of plants are considered as the variables in this study. The study found that out of four scenarios. However optimal routing flexibility combined with volume flexibility helps to achieve significant reduction in energy consumption. Finally, we offer future research questions on flexible operations management practices.
\end{abstract}

Keywords: Flexible Operations Management, Sustainable Operations Management, Energy Sustainability, Optimization, Discrete Event Simulation, Genetic Algorithm.

\section{Introduction}

In recent years due to intense competition and globalization, countries are trying to achieve rapid economic recovery through fast industrialization and 
liberal policies. Dell and Rand (2001) argued that the quality of life is dependent upon access to cheap supply of energy. Hence for a sustainable future, the energy should be derived from non-fossil sources; ideally, it should also be reliable and safe, flexible in use, affordable, and limitless. According to the Industrial Development Report (2013, p. 1), the manufacturing sector contributes one in six jobs globally. Energy consumption in the manufacturing sector is very high. Nearly $35 \%$ of total global production of electricity is only used for manufacturing activities. Manufacturing operations are responsible for nearly $20 \%$ of total global carbon emissions (Graedel et al., 2011). The World Bank (2007) reports that there is a 50\% increase in carbon gas emission from BRIC countries with in last two decades. Thus, there is a pressing need to protect our environment since any local environmental degradation will impact negatively on other regions of the world (Rosenbloom, 2001; Hoffman, 2001). Severo et al. (2015) argue that each company must adopt cleaner production which ensures minimum energy usage and maximum resource utilization. Uzzone et al. (2012) have argued for energy-aware scheduling (EAS) of manufacturing processes to optimally plan energy saving for a given schedule. Shojaeipour (2015) argues that environmental factors have a major role in selecting an optimal process planning schema. However, the systems that are currently available are barely capable of dealing with these environmental issues. Beside global energy crisis and highly uncertain environment, there is pressing need for flexible operations to overcome large magnitude of global challenges. Jayal et al. (2010) have argued that achieving sustainability in manufacturing requires a holistic view spanning not just the product and the manufacturing processes involved in its fabrication, but also the entire supply chain, including the manufacturing systems across multiple product lifecycles. Mahadevan et al. (2003) attempted to answer sustainability need of the manufacturing firms which are operating under uncertain environment. However Mahadevan et al. (2003) considered demand as being uncertain and also following a Poisson process. The decision problems for the remanufacturing facility have to do with when to release returned products to 
the remanufacturing line and how many new products to manufacture. However research has not addressed other dimensions of uncertainty which include supply uncertainty, obsolete technology, political uncertainty and particularly the energy crisis which have severe impacts on vehicle production. King and Lenox (2001) in one of their seminal works have noted that the lean and environmental performance may not be directly related. Hence lean production, as measured by ISO 9000 adoption and low chemical inventories, is complementary to waste reduction and pollution reduction. Though there is a sufficient amount of literature eon sustainable manufacturing or sustainable operations (see, Gunasekaran et al. 2013), the term flexible operations in context to energy sustainability has received less attention. Furthermore, literature on sustainable operations has made significant contributions to environmental dimension. Researchers have analyzed uncertainties and flexibilities of eco-driven or green supply chains (see Mirzapour et al., 2013 and Madaan \& Mangla, 2015), but however the role of the energy dimension on flexible sustainable operations is still underdeveloped. Hence in our study we study the impact of flexible operations and in particular the impact of optimum production batch size on energy sustainability which is missing link in the existing literature. In particular, we optimize the batch size of car bodies and routing options.

The guiding research questions of our research are:

i) What are the minimum changes to be done in the existing facility to accommodate two more upcoming models in the existing line without any productivity loss?

To answer our first research question we have adopted case research method. There are other alternative methods such as action research (AR) (see, Coughlan and Coghlan, 2002; Dey et al. 2014; De Carvalho et al., 2015), appreciative inquiry (Hanna et al. 2000), ethnographic (Barnes, 2001) and content analyses (Voss et al. 2002). Based on our extensive review of literature we found that the literature focusing on energy sustainability and flexible operations management practices is underdeveloped. Following Eisenhardt 
(1989) recommendations we felt that case research method will be highly suitable in our study. However the decision involved in-depth analyses of other alternative research methods. Initially we thought of AR as one of our members was a part of the project. Based on the definition offered by Coughlan and Coghlan (2002) we thought AR is highly suitable than case. But AR is about updating your understanding, theory, as one proceeds. This implies that once we start, we should have a model. Hence in this case we did not have a guiding theoretical model but we thought of carrying simulation using multiple cases to address our guiding question. Hence we finally selected case based approach.

ii) What is the optimum production batch size of variants for each product to ramp up the production and to minimize energy consumption?

We observed the optimum batch size, which minimizes the total energy consumption and maximizes throughput using a case in a car manufacturing company in Pune, India. In this study, however, we use a genetic algorithm in combination with discrete event simulation to achieve the desired output with minimum energy usage and avoiding nightshifts, which ensures better working atmosphere and work-life balance for employees (Onwubolu and Mutingi, 2001; Omar et al., 2015; Singh and Rajamani, 2012).

iii) What all are the routing and capacity flexibility scenarios that are to be explored to finish production within two shifts and to minimize energy consumption based on existing constraints?

To address this question we decided to use discrete event simulation in combination with genetic algorithms as a tool for the tactical capacity planning of a car production facility to deal with a multi objective decision-making production scenario, and to achieve better flexibility and sustainability by optimizing resources and energy consumption at plant level. 
The paper is organized as follows. After a brief review of the literature on flexible sustainable operations management, the problem and our methods are presented. Then follows our results and discussion, and the last section concludes the paper and presents limitations and future research directions.

\section{Literature Review}

\subsection{Flexible Operations Management}

Staying competitive is becoming more and more difficult, in the dynamic era of globalization. Bargaining power of consumers is rising due to the competition among global players with increasing demands for wide variety, best in class quality, better service, better reliability, faster delivery and highly customized products. Thus, organizations are forced to reduce the life span of products and to concentrate on speed, quality and costs simultaneously (Laugen et al., 2005). Generally the term 'flexibility' in operations management is meant to have flexibility in operations, volume and in supply (Duclos et al., 2003). There is a rich body of literature available in flexible operations management (see Winkler, 2009; Kumar et al. 2008; Barad\& Sapir, 2003; Das \& Abdel-Malek, 2003; Wiendahl and Dombrowski, 1987). Flexibility attributes add more dynamic capabilities to meet the uncertainties in operations in a better way and is a competitive advantage to the firm (Dubey et al. 2015; Fayezi et al., 2014; Reuter et al., 2010). Scholars (Hyun and Ahn 1992; Gerwin 1993; Beach et al. 2000; Seebacher and Winkler, 2014) suggest that manufacturing flexibility acts as a firm response to a dynamic business environment. Research has underlined the importance of the business environment in enabling flexibility to flourish, as well as its influence on business performance (Browne et al. 1984; Sethi and Sethi 1990). There are six dimensions of manufacturing flexibility: 'product', 'sourcing', 'volume', 'material-handling', 'mix' and 'routing' flexibility (Browne et al., 1984; Sethi and Sethi, 1990). They are defined as follows: 
(a) Product Flexibility: Product flexibility of a firm is its capability to launch new or improved products quickly into the market. Browne et al. (1984) defined this dimension as the potential to profitably and rapidly generate new set of products. It represents the capability to alter the mix of products in the ongoing manufacturing process.

(b) Sourcing Flexibility: Sourcing flexibility can be defined from two viewpoints. From the first view, it is the capability of a system to change the supplier base as per the company's requirement while, the second viewpoint focuses on the ability of a supplier to fulfill the changing demands of a focal firm. It refers to the firm's ability to maintain a multiple supplier base for any particular product or raw material.

(c) Volume Flexibility: Volume flexibility represents the ability of the manufacturing system to manage the production volume based on the changing market demand where the firms need an excessive coordination mechanism between the supply chain partners.

(d) Material-Handling Flexibility: Material-handling flexibility is the capability of a system to expeditiously shift various parts for right placing and processing within the manufacturing facility (Sethi and Sethi, 1990).

(e) Mix Flexibility: It refers to the capability of a firm to changeover the process rapidly and smoothly (Sethi and Sethi 1990).

(f) Routing Flexibility: Routing flexibility is the ability to produce the same product-mix by using different production routes available within the firm (Sethi and Sethi 1990).

However in our study we focus on volume and routing flexibility and its impact on energy sustainability as we have argued in our initial discussions.

\subsection{Sustainable Operations Management}

Sustainable Operations Management is the set of skills and concepts that allow an organization to control and align its business processes to obtain 
competitive returns on its capital assets without sacrificing the genuine needs of internal and external stakeholders and by ensuring zero negative impacts of its operations on people and the environment (Kleindorfer et al. 2005). According to Duque Ciceri et al. (2009), sustainability is the quality that allows something to be preserved, maintained and kept for tomorrow. Environmental, economic, social and technological are considered as the major dimensions of sustainability (Baud, 2008). Manufacturing includes all activities that are connected to each other from the production plant to the end customer intended to fulfill various human needs. There is a rich literature body in sustainable manufacturing and operations (see Garbie, 2013; Gunasekaran \& Spalanzani, 2012; Gimenez et al., 2012; Dubey et al. 2015). However, there is limited literature that has attempted to highlight the differentiating factors for achieving sustainable operations using alternative research methods.

\subsection{Energy Sustainability and Flexible Operations Management}

Researchers have rarely attempted to explore impacts of flexible operations on energy sustainability. It is becoming a complex task for organizations as they have to maintain flexibility attributes without sacrificing the sustainability principles. In particular, scholars have rarely attempted to explore the possibility of combining flexibility and sustainability by using operations research techniques. Many researchers attempted to analyze and optimize energy consumption in manufacturing systems by using simulation (see Herrmann et al., 2011; Thiede et al., 2011). However the literature focusing on flexible manufacturing and sustainable operations is extensive. Hence, we wish to explore the concept of flexible sustainable operations management in which the principles of flexible operations management need to be integrated with energy sustainability.

\section{Case study}

We have decided to use a company which we will refer to as XYZ Automotive Ltd. which is located at Pune, Maharashtra, India. The particular company is 
one of the leading companies in India that is interested in sustainable practices, including energy consumption and resource allocation. XYZ currently produces five models coded as: $\mathrm{XA}, \mathrm{XB}, \mathrm{XO}, \mathrm{XZ}$ and $\mathrm{YI} . \mathrm{XB}, \mathrm{XZ}$, and YI are existing products and the company is planning to add two more products, XA and $\mathrm{XO}$ to its production line within two years. The assembly process contains power train shop, press shop, weld shop, paint shop, and assembly shop (known as TCF). In our study we have considered the production flow starting from the weld shop only. Hence, the body flow starting from weld shop to final assembly shop via paint shop is the focus of our study. There is a six meter height buffer zone which can occupy 80 power and free carriers with car bodies in between weld shop and paint shop called weld body storage (WBS). There is one more buffer zone which can occupy 320 power and free carriers with car bodies in between the paint shop and the assembly shop. The firm has differential rate of production and different working hours for each shop. The company has another facility at Nashik, in which only paint shop and assembly shop can be utilized. It is a joint investment with another automotive manufacturer that helps to have capacity and routing flexibility. The car bodies are sent to Nashik Plant after completing welding at Pune.

Approximate values of average energy consumption per vehicle for different shops in the plant are given in Table 1. Projected requirements of the cars are shown in Table 2.

Table 1: Average energy consumption per vehicle

\begin{tabular}{|c|c|c|l|}
\hline Production Shop & $\begin{array}{c}\text { Average Power } \\
\text { Consumption/Vehicle } \\
\text { while working }\end{array}$ & $\begin{array}{c}\text { Average Power } \\
\text { Consumption/Vehi } \\
\text { cle while setting- } \\
\text { up }\end{array}$ & $\begin{array}{l}\text { Standby } \\
\text { energy }\end{array}$ \\
\hline Pune Weld Shop X Line & $76 \mathrm{Kw}$ & $65 \mathrm{Kw}$ & $40 \mathrm{Kw}$ \\
\hline Pune Weld Shop Y Line & $68 \mathrm{Kw}$ & $60 \mathrm{Kw}$ & $40 \mathrm{Kw}$ \\
\hline Pune Paint shop & $212 \mathrm{Kw}$ & $190 \mathrm{Kw}$ & $100 \mathrm{Kw}$ \\
\hline
\end{tabular}




\begin{tabular}{|c|c|c|c|}
\hline Pune TCF & $49 \mathrm{Kw}$ & $43 \mathrm{Kw}$ & $30 \mathrm{Kw}$ \\
\hline Nashik Plant Paint & $212 \mathrm{Kw}$ & $190 \mathrm{Kw}$ & $100 \mathrm{Kw}$ \\
\hline Nashik Plant TCF & $49 \mathrm{Kw}$ & $43 \mathrm{Kw}$ & $30 \mathrm{Kw}$ \\
\hline
\end{tabular}

Table 2: Projected requirement of car variants

\begin{tabular}{|l|l|l|l|l|}
\hline Variants & $\begin{array}{l}\text { Avg. } \\
\text { requirement } \\
\text { per day for } \\
\text { FY 15-16 }\end{array}$ & $\begin{array}{l}\text { Avg. } \\
\text { requirement } \\
\text { per day for } \\
\text { FY 16-17 }\end{array}$ & $\begin{array}{l}\text { Avg. } \\
\text { requirement } \\
\text { per day for } \\
\text { FY 17-18 }\end{array}$ & $\begin{array}{l}\text { Avg. } \\
\text { requirement } \\
\text { per day for } \\
\text { FY 18-19 }\end{array}$ \\
\hline XO & No Production & 152 & 186 & 220 \\
\hline XA & No Production & No Production & 143 & 273 \\
\hline XB & 152 & 187 & 168 & 127 \\
\hline XZ & 170 & 203 & 152 & 118 \\
\hline YI & 158 & 118 & 0 & 0 \\
\hline
\end{tabular}

\section{Case scenarios}

Four different options are available for the company to improve the total throughput of the system, which are treated as four different cases in our study:

Case 1: Existing scenario

Since the requirement is very much lower than the available capacity, production batch size was not considered as a critical parameter. The company would like to avoid adding a third shift and to utilize the plant at Nashik, the plant was run at $15 \mathrm{JPH}$ (job per hour) without optimizing the batch size. There was only one unloading device at Nashik, with a capacity of 15 jobs per hour. Hence, currently $\mathrm{XZ}$ and $\mathrm{YI}$ car bodies are routed to Nashik Plant after completing the welding process from Pune plant. 
Case 2: Nashik Plant at 15 JPH with optimized batch size

Optimization of batch size helps reduce congestion occurring in the route, reduce set-up time and minimize energy utilization. Optimization of batch size will help to get improved throughput, which must be checked against the projected requirement for new models.

Case 3: Nashik Plant at 25 JPH with optimized batch size

The bottleneck at the cab unloading process at Nashik Plant can be overcome by installing one more lift with a substantial investment. In this case, the JPH will get improved from 15 to 25 .

Case 4: Routing all XO variants to Pune Plant itself \& Nashik Plant at 15JPH $\mathrm{XO}$ and $\mathrm{XZ}$ can be produced either in Pune or Nashik plant after finishing welding process from Pune plant. Hence, instead of investing for a new unloading device at Nashik plant, routing option of $\mathrm{XO}$ to existing Pune plant is to be checked with throughput and energy utilization.

Table 3: Manufacturing scheme

\begin{tabular}{|c|c|c|c|c|c|c|}
\hline \multicolumn{7}{|c|}{ Manufacturing Scheme } \\
\hline \multirow{2}{*}{ Model } & \multicolumn{3}{|c|}{ Pune Plant } & \multicolumn{3}{c|}{ Nashik Plant } \\
\cline { 2 - 7 } & Weld & Paint & TCF & Weld & Paint & TCF \\
\hline$Y I$ & $\checkmark$ & X & X & X & $\checkmark$ & $\checkmark$ \\
\hline$X B$ & $\checkmark$ & $\checkmark$ & $\checkmark$ & X & X & X \\
\hline$X Z$ & $\checkmark$ & $\checkmark$ & $\checkmark$ & $X$ & $\checkmark$ & $\checkmark$ \\
\hline$X O$ & $\checkmark$ & $\checkmark$ & $\checkmark$ & $X$ & $\checkmark$ & $\checkmark$ \\
\hline$X A$ & $\checkmark$ & $\checkmark$ & $\checkmark$ & $X$ & $\checkmark$ & $\checkmark$ \\
\hline
\end{tabular}

Variant specific production scheme is to be followed in the production system. That is, YI variant can only be produced in Nashik shop and cannot be routed 
to Pune paint or TCF shop. Similarly, XZ can be produced in both the plants but in the worst case only the variant will be taken to the Pune paint and TCF shops. The details of the manufacturing scheme are shown in Table3. Shift timings and break schedule are different for each shop. The details of shift schedules are given in Table 4, which are incorporated in the model.

Table 4: Differential Shift breaks details

\begin{tabular}{|lc|c|c|c|}
\hline \multicolumn{4}{|c|}{ Pune / Nashik Plant: Shift Pauses } \\
\hline \multicolumn{2}{|c|}{ Model } & \multicolumn{3}{c|}{ Shift Break Details } \\
\hline & Weld & Paint & TCF \\
\hline Shift 1 & $\mathbf{( 6 : 3 0 -}$ & $8: 15-8: 30 ;$ & $8: 15-8: 30 ;$ & $8: 15-8: 30 ;$ \\
& $11: 30-12: 00 ;$ & $12: 00-$ & $11: 30-12: 00 ;$ \\
& $13: 20-13: 30$ & $12: 30 ;$ & $13: 20-13: 30$ \\
& & & $13: 20-$ & \\
Shift 2 & $\mathbf{( 1 5 : 0 0 -}$ & $17: 15-17: 30 ;$ & $17: 15-$ & $17: 15-17: 30 ; 19: 30-$ \\
23:30) & & $19: 30-20: 00 ;$ & $17: 30 ;$ & $20: 00 ;$ \\
& $21: 00-21: 10$ & $20: 00-$ & $21: 00-21: 10$ \\
& & & $20: 30 ;$ & \\
\hline Shift 3 & $\mathbf{( 2 3 : 3 0 -}$ & No third Shift for Weld & $2: 00-2: 20$ & No third Shift for TCF \\
6:30) & & shop & & shop \\
\hline
\end{tabular}

Model specific setup time for each shop is different. Different set-up time matrices are incorporated for different shops and an example of such setup time matrix is shown in Figure 1 (Screenshot). 


\begin{tabular}{|c|c|c|c|c|c|}
\hline & $\begin{array}{l}\text { string } \\
\text { ô }\end{array}$ & $\begin{array}{l}\text { time } \\
1\end{array}$ & $\frac{\text { time }}{2}$ & $\begin{array}{l}\text { time } \\
3\end{array}$ & $\begin{array}{l}\text { time } \\
4\end{array}$ \\
\hline string & & $x 0$ & $\mathrm{XB}$ & $x z$ & $\mathrm{XA}$ \\
\hline 1 & - & & & & \\
\hline 2 & $x 0$ & 0.0000 & $5: 00.000$ & 5:00.0000 & $5: 00.000$ \\
\hline 3 & $\mathrm{XB}$ & $5: 00.0000$ & $5: 00.000$ & 5:00,0000 & $5: 00,000$ \\
\hline 4 & $x z$ & $5: 00.0000$ & $5: 00,000$ & $5: 00.0000$ & $5: 00,000$ \\
\hline 5 & XA & 5:00.0000 & $5: 00.000$ & $5: 00.0000$ & 0.0000 \\
\hline
\end{tabular}

Figure 1 (Screenshot): Setup time data

The Pune weld shop contains two lines, X line and Y line. Each line contains separate metal finish lines (MFLs) on which assembly of closure such as doors, fender, and hood are taking place. X line can accommodate models such as XB and $\mathrm{XZ}$ and $\mathrm{Y}$ line produces $\mathrm{YI}$ model. In near future, model $\mathrm{XA}$ and $\mathrm{XO}$ will be getting added to the $\mathrm{X}$ line, and $\mathrm{XO}$ models will be getting transferred to $\mathrm{Y}$ metal finish line instead of transferring to $\mathrm{X}$ metal finish line to balance the capacity.

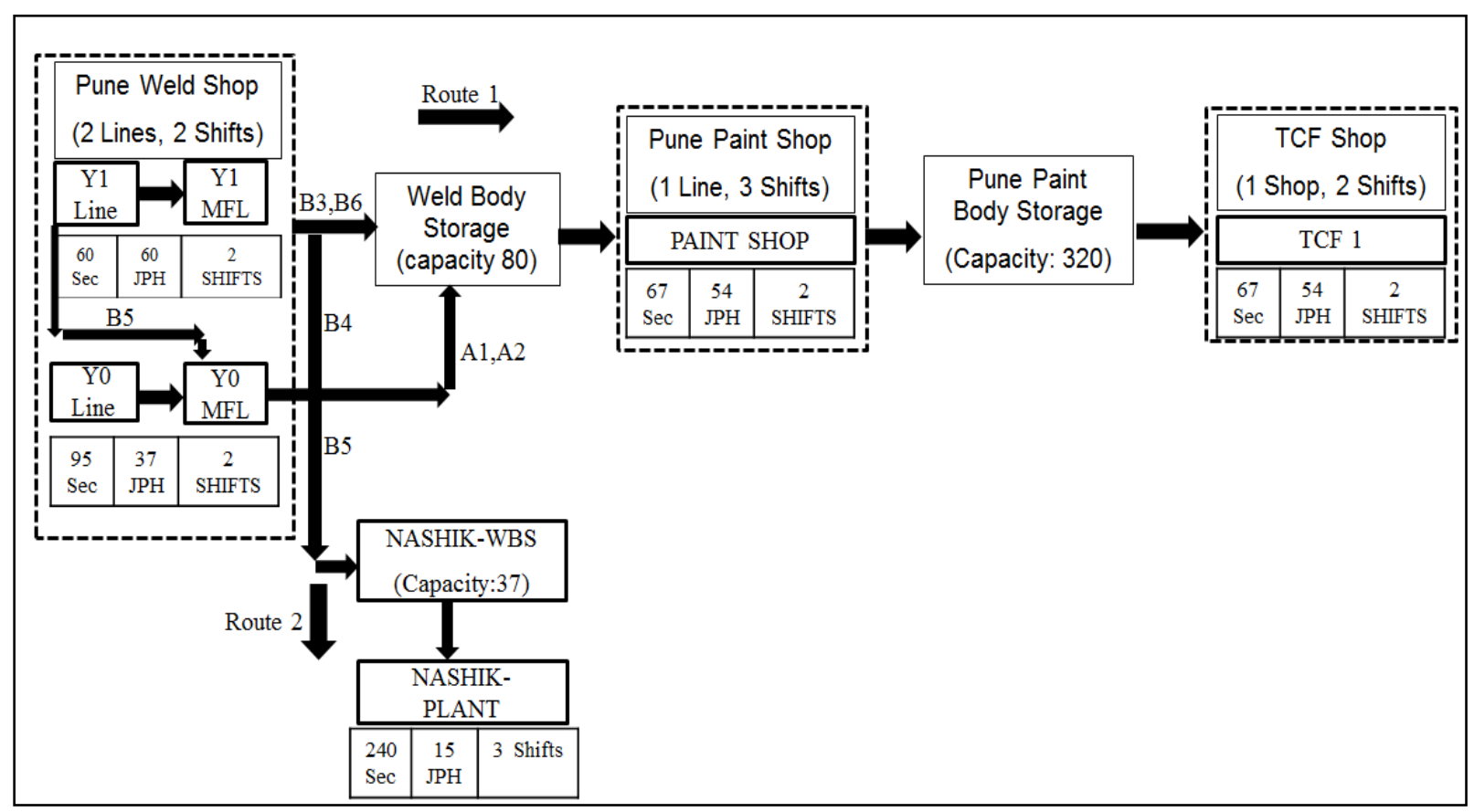

Figure 2: Body flow scheme 
There is flexibility to send XZ, XO and YI models to Nashik plant, to maintain capacity and routing flexibility. Differential production capacity and cycle time details of the shops in the system under study are shown in Figure 2.

\subsection{Discrete event simulation}

Discrete event simulation is a widely accepted tool for analyzing complex manufacturing, logistics and inventory optimization problems. It is one of the most popular and widely accepted methodologies used to analyze the dynamic complex production level energy analysis (Omar et al., 2015; Johansson et al., 2009; Wohlgemuth et al., 2006; Joseph \& Sridharan, 2011) and to optimize manufacturing facilities to achieve sustainable production.

\subsection{Genetic algorithms in combination with discrete event simulation}

Genetic Algorithm (GA) is a non-traditional optimization method. A GA is a structured and randomized search strategy in which weak solutions are replaced by combining strong and fittest individuals in successive iterations (Singh and Rajamani, 2012). There is a rich body of research using GA in manufacturing and production optimization problems (see Onwubolu and Mutingi, 2001; Joines et al., 1996; Moon and Kim, 1999). The base of any genetic algorithm search tools is on genetic reproduction processes and "survival of the fittest" strategies. The use of GA in combination with discrete event simulation helps organizations to optimize complex scheduling problems prevailing in a dynamic flow production system (Azzaro-Pantel et al., 1998). Lins \& Droguett $(2009,2011)$ and solve multi-objective production problems effectively. Lins \& Droguett (2011) further argue that using a combination of search methodologies with discrete event simulation helps improve the reliability of the analysis. Oyarbide-Zubillaga (2008) and Azadivar \& Wang (2000) are examples of research that uses a combination of search algorithms with discrete event simulation. 


\subsubsection{Problem statement}

Equivalent energy per vehicle per shop is an input as the sum of "plant level" consumption and "process level" consumption. Energy spent for maintaining the working environment of the plant is referred to as the "plant" level consumption (Galitsky, 2008; Boyd, 2005) and energy spent for actual production, which is referred as "process" level consumption (Rahimifard et al., 2010). We further develop our methodology in the next subsections.

\subsubsection{The mathematical model}

A mathematical model has been formulated with an objective function followed by constraints. A mixed-integer formulation of the flexible sustainable production planning system design approach is presented below. The following notations are used to develop the mathematical representation of the objective function and design constraints.

Indexing set

$$
\begin{array}{ll}
i: & \text { Car variant index } i=1,2, \ldots I \\
j: & \text { Plant index } j=1,2 \ldots . J \\
m: & \text { Time period counted in days } m=1,2, \ldots M
\end{array}
$$

System parameters

$S T_{j}: \quad \quad$ Shift timing available for plant $j$, excluding shift breaks

$P R_{i e}: \quad$ equivalent projected requirement of variant $i$

$C_{i j}: \quad \quad$ Rated capacity of plant $j$ for variant $i$

$Q_{i j m}: \quad \quad \quad$ Quantity of car variant $i$ produced in plant $j$ during time period $m$

$W P_{i j}$ : $\quad$ Average power consumption per vehicle type $i$ in plant $j$ during working time

$S P_{i j}: \quad \quad \quad \quad$ Average power consumption per vehicle type $i$ in plant $j$ during setting up period

$B P_{i j}: \quad \quad \quad \quad \quad \quad \quad$ verage power consumption per vehicle type $i$ in plant $j$ during blockage or waiting or standby time period 
Decision variables

$r_{i j}$ : $\quad$ Routing of variant $i$ in plant $j$ (Binary routing variable, 1 if yes, $O$ if no)

$f_{i j:} \quad \quad$ Working time of model $i$ in plant $j$

$g_{i j}$ : $\quad$ Production setup time period for $i$ in plant $j$

$l_{i j}$ : $\quad$ Waiting time period of model $i$ at any work station in plant $j$

Objective function is to minimize the total energy consumption:

Minimize

$T E C=\sum_{m=0}^{M} \sum_{j=0}^{J} \sum_{i=0}^{I} Q i j * f i j * W P i j * r i j+\sum_{m=0}^{M} \sum_{j=0}^{J} \sum_{i=0}^{I} Q i j * g i j * S P i j *$

$r i j+\sum_{m=0}^{M} \sum_{j=0}^{J} \sum_{i=0}^{I} Q i j * l i j * B P i j * r i j$

Subjected to:

$\sum_{i=0}^{I} \sum_{j=0}^{J} Q i j * r i j \geq$ PRie

$P R i e=\frac{P R i 1+P R i 2+\ldots \ldots \ldots . . P R i M}{M}$

$\sum_{i=0}^{I} \sum_{j=0}^{J} f i j * r i j+\sum_{i=0}^{I} \sum_{j=0}^{J} g i j * r i j+\sum_{i=0}^{I} \sum_{j=0}^{J} l i j * r i j \leq S T j$

$\sum_{i=0}^{I} \sum_{j=0}^{J} Q i j * r i j \leq \sum_{i=0}^{I} \sum_{j=0}^{J} C i j$

Non-negativity constraints:

$\begin{array}{ll}P R_{i m} \geq 0 & \forall i \\ S T_{j} \geq 0 & \forall j \\ C_{j m} \geq 0 & \forall j, m \\ Q_{i j m} \geq 0 & \forall i, j, m\end{array}$

As mentioned above, this paper aims at minimizing the total plant level energy consumption. Energy consumption has three different components: energy consumption during working, during waiting period of machines, and setting up time period. These three different components are represented by three different parts of the objective function shown in equation 1. However, maximization functions are usually used as fitness functions with genetic algorithms. The minimization objective function value is transformed into 
maximization fitness function value. Thus the fitness function is the maximization of throughput in the pre-specified fixed shift time available, which in effect will be the minimization of total energy consumption by minimizing non-value adding setting up time and waiting time. Constraint 2 shows that the sum of quantities of each variant produced in plants must be greater than or equal to the equivalent requirement of variant $i$. Equation 3 is used to calculate the equivalent demand of variant $i$, which is the average of demand over the time period $m$. Constraint 4 is used to indicate that the total time consumed for working, waiting and setting up must be less than or equal to the total shift time available. Constraint 5 is used to represent that the total quantity produced in any plant must be less than or equal to the rated capacity of that particular plant. Equations 6 to 9 represents non-negativity constraints, such that the values of variables such as projected requirement, shift timing available, rated capacity of plants and quantity produced in plants must be non-negative.

\subsection{Determination of GA parameters}

Before starting with the simulation runs, different parameters of GA were fixed based on initial experimentation. The parameters included population size, number of generations, termination criteria, input parameters and fitness function. We have come across two different well-known termination criteria from literature (Pillai \& Subbarao, 2008). The first one checks the improvement from generation to generation. As per the first criteria, the algorithm stops if there is no improvement in the best solution obtained from a pre-specified number of generations. As per the second criteria, the algorithm stops when the maximum number of generation specified is reached. We have used a mix of these two criteria for the simulation runs and checked for a steady state by changing the number of generations and size of generations randomly. We found that, with a population size of 150 , and 20 numbers of generations there will be a total of 3000 simulation iterations, which would give a near steady state condition. These parameters are kept constant for all cases analyzed in 
this study. Since the quality of solution obtained using genetic algorithm is depended on population size and the number of generations (Gupta et al., 1996), further experimentation is to be used to find out the optimum population size and number of generations.

\subsection{Fitness Function}

A GA mimics the survival-of-the-fittest principle of nature to make a search process (Goldberg, 1989). Therefore, GAs is naturally suitable for solving maximization problems. The operation of GAs begins with a population of strings representing design or decision variables. A chromosome's potential as a solution is determined by its fitness function, which evaluates a chromosome with respect to the objective function of the optimization problem. Fitness function is first derived from objective function and used in successive genetic operations. For maximization problems, the fitness function can be considered to be the same as the objective function. Table 5 shows the genetic algorithm search strategy adopted in this problem, and Figure 3 extrapolates the distribution of offspring based on fitness values.

Table 5: Multi-objective GA parameters

\begin{tabular}{|c|c|}
\hline Parameter & Value \\
\hline Population size & 150 \\
\hline Number of generations & 20 \\
\hline Optimization parameter & $\begin{array}{c}\text { Batch sizes of Cab } \\
\text { variants }\end{array}$ \\
\hline Type & Maximization \\
\hline Fitness function & System throughput \\
\hline
\end{tabular}




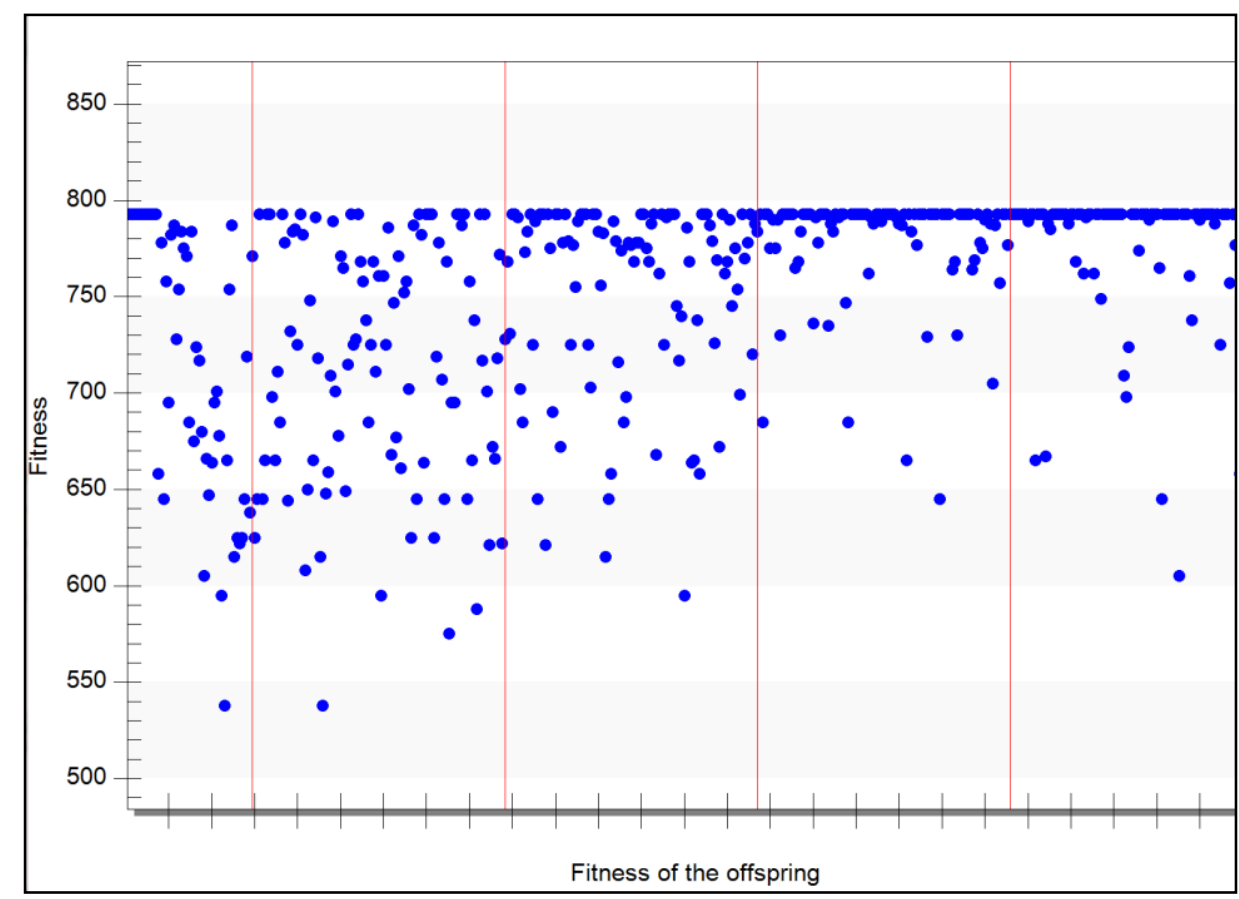

Figure 3: Offspring distribution based on fitness values

\section{Procedure}

Our study started by modeling the existing production and routing system by incorporating cycle times, energy consumption, set-up time and routing options for existing variants. Four different cases were to be checked to find out the best feasible option. Steps involved in the analysis include:

Step 1: Model the existing production system.

Step 2: Check the throughput and validating the system with shift timings, energy consumption and routing constraints.

Step 3: Check for the required throughput by adding upcoming models in the existing lines by using a fixed batch size of ten for all models.

Step 4: Check throughput by running Nashik Plant at existing capacity of 15JPH but with optimized batch size of car variants with the help of genetic algorithm tool in the simulation tool. 
Step 5: Check throughput by running Nashik Plant at an improved capacity of 25JPH but with a fixed batch size of ten for all models.

Step6: Check throughput by running Nashik Plant at existing capacity of $25 \mathrm{JPH}$ but with optimized batch size of car variants with the help of genetic algorithm tool in the simulation tool.

Step 7: Check throughput by routing all XO variants to Pune Plant itself and running Nashik Plant at $15 \mathrm{JPH}$.

Step 8: Select the cases where the required throughput is met for further energy consumption analysis by using energy analyzer tool, with an optimized batch size by using genetic algorithm optimizer.

Step 9: Find out the best feasible option in which required throughput is met by running the factory for minimum time within two shifts at minimum energy consumption level.

\subsection{Results}

The GA optimization shows that the maximum achievable throughput per day is 800 , with an optimized batch size and specified sequence. The search algorithm shows the progress of fitness function value for different batch size combinations of cab variants and is shown in Figure 4 . The batch size that corresponds to the best throughput is used for energy analysis and the graphical representation of energy analysis is shown in Figure 5. 


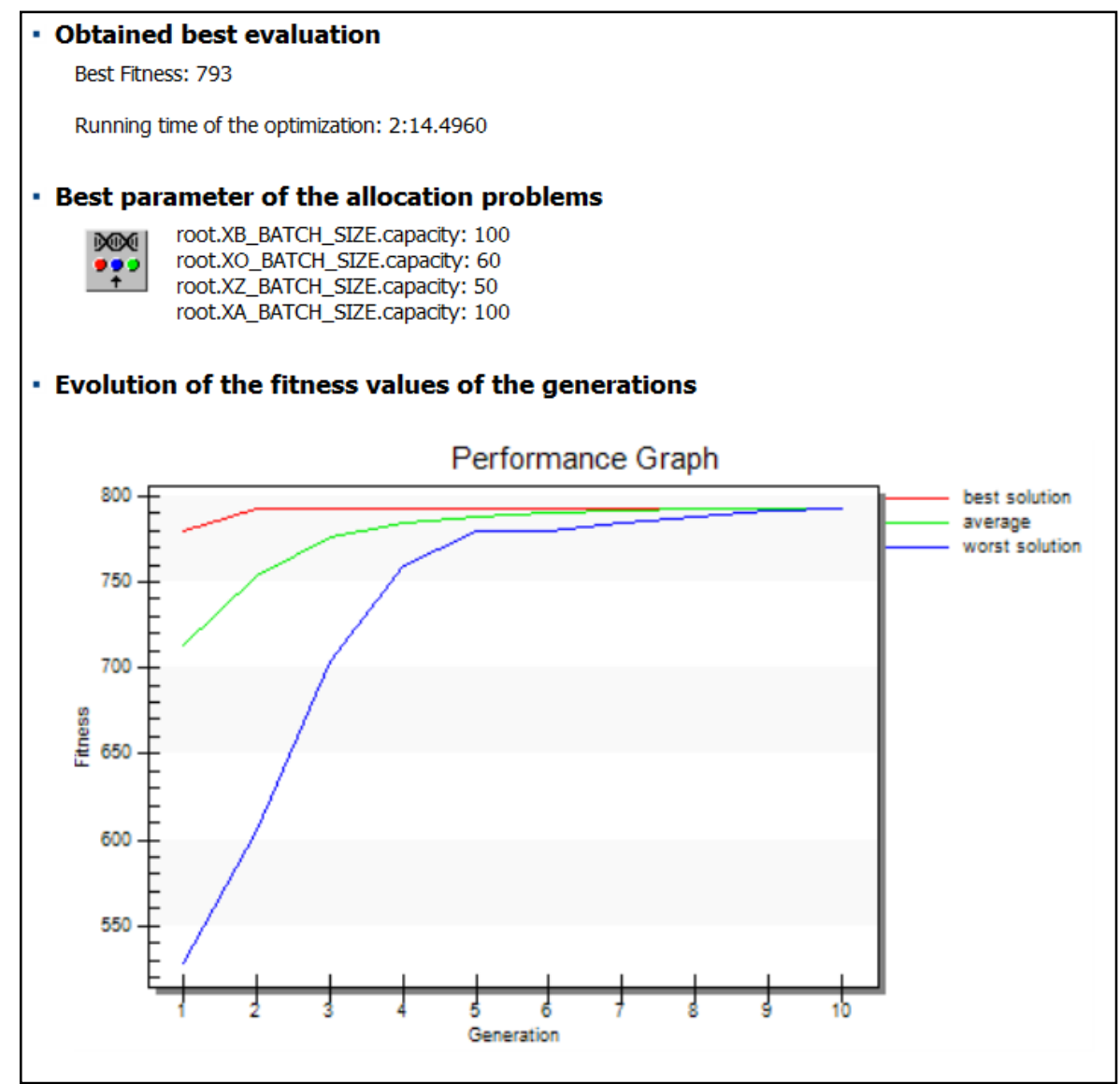

Figure 4: Genetic algorithm fitness value analysis output

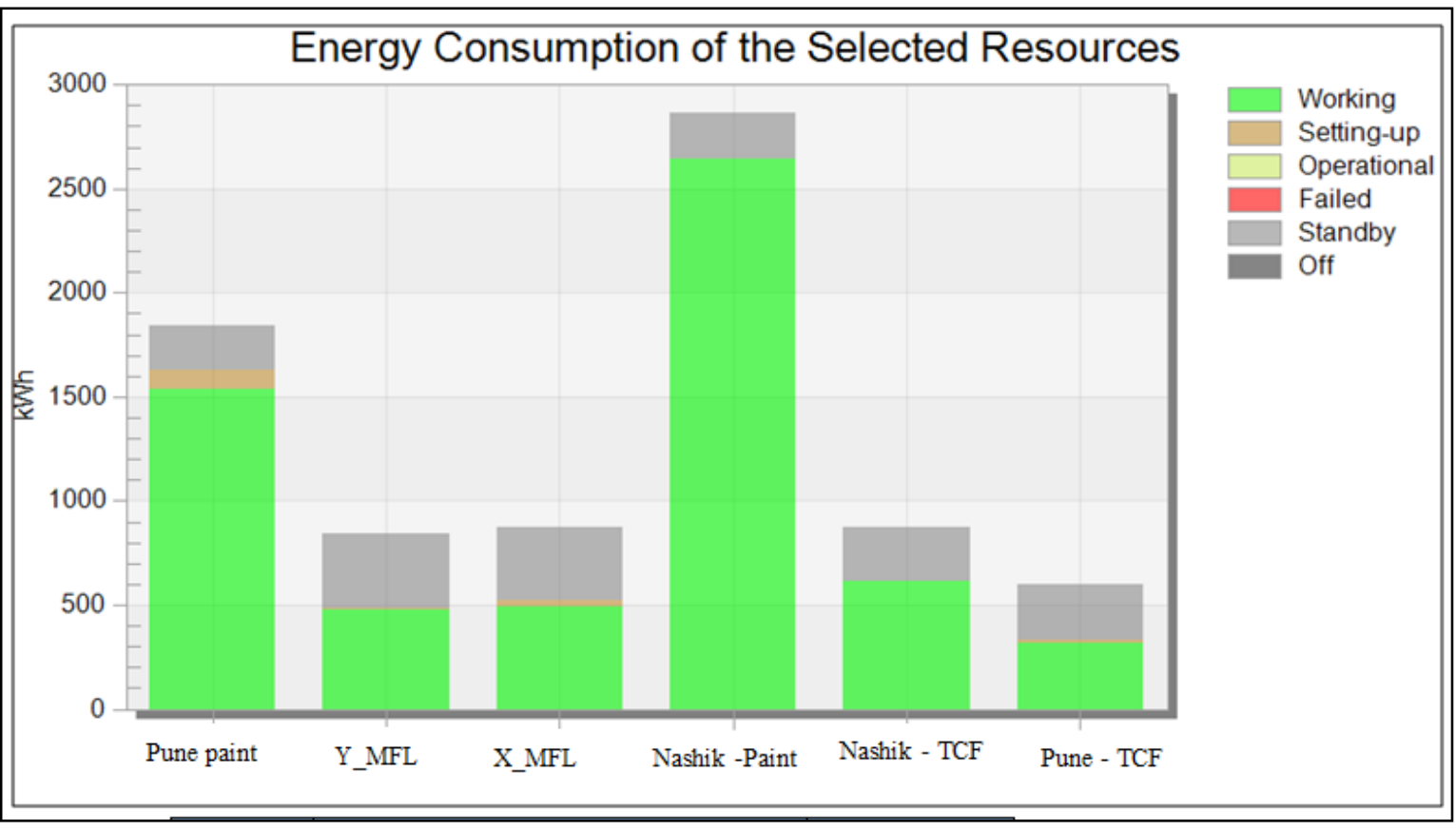

Figure 5: Energy analysis output 
The four different cases have been simulated to check whether the requirement is being met with the existing differential shift schedules and rated production. It appeared that in the first two cases it is not possible to meet the projected requirement. Hence, they were dropped without further analyses. But the requirements were met within the scheduled production time in the remaining two cases. The next question is, which one must be taken ahead as the final proposal. The answer was clear that the case in which energy consumption is minimal must be taken ahead. Table 6 extrapolates the summary of results for the different cases analyzed.

Table 6: Summary of results in first phase

\begin{tabular}{|c|c|c|}
\hline Cases & Description & Requirement \\
\hline Case1 & $\begin{array}{c}\text { Case 1 Nashik Plant15 JPH } \\
\text { without optimizing the batch } \\
\text { size }\end{array}$ & NOT MET \\
\hline Case 2 & $\begin{array}{c}\text { NASHIK PLANT15 Nashik } \\
\text { Plant by optimizing the batch } \\
\text { size }\end{array}$ & NOT MET \\
\hline Case 3 & $\begin{array}{c}\text { NASHIK PLANT25 JPH and by } \\
\text { optimizing the batch size }\end{array}$ & MET \\
\hline Case 4 & $\begin{array}{c}\text { All XO Pune Plant itself } \\
\text { (Route1) }\end{array}$ & MET \\
\hline
\end{tabular}

Further analysis of the case 3 and case 4 by using the energy analyzer tool in the plant simulation module gave a clear picture of total energy consumption for each plant per day. Since there is a predefined setup time for each plant, energy consumption depended on the batch size of variants and the routing options adopted. Since the routing and batch sizes were different for each case, there was a significant difference in the energy consumption levels for plants. A summary of plant-level energy consumption for case 3 and case 4 is shown in table6. Analysis showed that there will be a savings of $92 \mathrm{KW}$ per day, 
Table 7: Proposed batch size which ensures minimum energy consumption

\begin{tabular}{|c|c|c|c|c|}
\hline Variants & $\begin{array}{c}\text { Batch size for } \\
\text { FY 15-16 }\end{array}$ & $\begin{array}{c}\text { Batch size for } \\
\text { FY 16-17 }\end{array}$ & $\begin{array}{c}\text { Batch size for } \\
\text { FY 17-18 }\end{array}$ & $\begin{array}{c}\text { Batch size for } \\
\text { FY 18-19 }\end{array}$ \\
\hline XO & No Production & 90 & 60 & 50 \\
\hline XA & No Production & No Production & 60 & 100 \\
\hline XB & 60 & 50 & 60 & 30 \\
\hline XZ & 30 & 70 & 40 & 40 \\
\hline YI & 10 & 10 & No Production & No Production \\
\hline
\end{tabular}

Table 8: Plant level energy consumption

\begin{tabular}{|c|c|c|c|c|c|c|c|}
\hline \multicolumn{8}{|c|}{ Case 3: Nashik Plant $25 \mathrm{JPH}$ able to meet all XZ XO YI to route 2} \\
\hline \multicolumn{2}{|c|}{ Year 1} & \multicolumn{2}{|c|}{ Year 2} & \multicolumn{2}{|c|}{ Year 3} & \multicolumn{2}{|c|}{ Year 4} \\
\hline $\begin{array}{l}\text { Paint } \\
\text { Shop }\end{array}$ & 1674.08 & $\begin{array}{l}\text { Paint } \\
\text { Shop }\end{array}$ & 1843.67 & $\begin{array}{l}\text { Paint } \\
\text { Shop }\end{array}$ & 1855.17 & $\begin{array}{l}\text { Paint } \\
\text { Shop }\end{array}$ & 2131.58 \\
\hline Y_MFL & 630.89 & Y_MFL & 839.43 & Y_MFL & 604.54 & Y_MFL & 739.8 \\
\hline X_MFL & 782.87 & X_MFL & 873.33 & X_MFL & 1037.6 & X_MFL & 1061.47 \\
\hline $\begin{array}{c}\text { Nashik } \\
\text { Paint }\end{array}$ & 2576.93 & $\begin{array}{c}\text { Nashik } \\
\text { Paint }\end{array}$ & 2862.43 & $\begin{array}{c}\text { Nashik } \\
\text { Paint }\end{array}$ & 2793.27 & $\begin{array}{c}\text { Nashik } \\
\text { Paint }\end{array}$ & 3162.47 \\
\hline $\begin{array}{c}\text { Nashik } \\
\text { TCF }\end{array}$ & 810.53 & $\begin{array}{c}\text { Nashik } \\
\text { TCF }\end{array}$ & 876.52 & $\begin{array}{c}\text { Nashik } \\
\text { TCF }\end{array}$ & 850.03 & $\begin{array}{c}\text { Nashik } \\
\text { TCF }\end{array}$ & 931.17 \\
\hline TCF_1 & 563.42 & TCF_1 & 596.71 & TCF_1 & 594.67 & TCF_1 & 637.29 \\
\hline \multicolumn{8}{|c|}{ Case 4: Nashik Plant at $15 \mathrm{JPH} \&$ all XO routed to Pune } \\
\hline \multicolumn{2}{|c|}{ Year 1} & \multicolumn{2}{|c|}{ Year 2} & \multicolumn{2}{|c|}{ Year 3} & \multicolumn{2}{|c|}{ Year 4} \\
\hline $\begin{array}{l}\text { Paint } \\
\text { Shop }\end{array}$ & 1674.08 & $\begin{array}{l}\text { Paint } \\
\text { Shop }\end{array}$ & 2531.75 & $\begin{array}{l}\text { Paint } \\
\text { Shop }\end{array}$ & 2654.5 & $\begin{array}{l}\text { Paint } \\
\text { Shop }\end{array}$ & 3135 \\
\hline Y_MFL & 630.89 & Y_MFL & 560.62 & Y_MFL & 353.33 & Y_MFL & 353.33 \\
\hline X_MFL & 782.87 & X_MFL & 1074.53 & X_MFL & 1231.73 & X_MFL & 1357.47 \\
\hline $\begin{array}{c}\text { Nashik } \\
\text { Paint }\end{array}$ & 2576.93 & $\begin{array}{c}\text { Nashik } \\
\text { Paint }\end{array}$ & 2520.4 & $\begin{array}{c}\text { Nashik } \\
\text { Paint }\end{array}$ & 2068.13 & $\begin{array}{c}\text { Nashik } \\
\text { Paint }\end{array}$ & 1884.4 \\
\hline $\begin{array}{c}\text { Nashik } \\
\text { TCF }\end{array}$ & 810.53 & $\begin{array}{c}\text { Nashik } \\
\text { TCF }\end{array}$ & 797.47 & $\begin{array}{c}\text { Nashik } \\
\text { TCF }\end{array}$ & 692.93 & $\begin{array}{c}\text { Nashik } \\
\text { TCF }\end{array}$ & 650.46 \\
\hline TCF_1 & 563.42 & TCF_1 & 735.32 & TCF_1 & 751.05 & TCF_1 & 846.81 \\
\hline
\end{tabular}


if we go for case 3 instead of case 4 . Table 7 shows the proposed batch size allocation that ensures maximum energy utilization, whereas Table 8 shows the energy consumption data for the two alternative cases analyzed.

\subsection{Discussion}

Our interest in investigating the role of flexible operations management on energy sustainability was triggered by two facets of vehicle manufacturers. Firstly, due to uncertainty. As we argued uncertainty stems from demand fluctuations, supply constraints, obsolete technology, political instability, and energy crisis. However studies focusing on role of flexible operations management on energy sustainability have attracted less attention in comparison to demand uncertainty, supply uncertainty and technology uncertainty. Secondly, prior models have focused on waste reduction and cost minimization. However, the optimum batch size and its impact on energy sustainability have received less attention. Under these circumstances we argue that multiple case based approach to investigate the role of flexible operations on sustainable operations is equally, if not more relevant for understanding energy sustainability. Hence our current findings support the prior findings (King and Lenox, 2001) and further extend previous research (see Mahadevan et al. 2003) that has only considered demand uncertainty. Previous research (see Mirzapour et al., 2013 and Madaan \& Mangla, 2015) has recognized the need for flexible operations. However these studies have ignored energy sustainability. Thus by investigating energy sustainability using volume and routing flexibility we have made significant contribution to energy sustainability literature and operations flexibility.

\subsubsection{Theoretical Implications}

Flexible operations and energy sustainability are well discussed in the operations management literature. What is less understood is how flexible operations impact energy sustainability. The two key aspects of this study signify our contributions to theory. Firstly, the integration of two independent 
concepts (i.e. flexible operations management and energy sustainability); and secondly, the case based approach to study the impact of optimum batch size on energy sustainability. Hence the study findings suggest that the routing flexibility combined with volume flexibility have implications on TCE.

\subsubsection{Practice Implications}

The findings of the study suggest that energy consumption can be significantly reduced if routing and volume flexibility are both considered in the objective function. The findings provide further insights to those organizations need to decide whether to consider routing flexibility or volume flexibility or both. If volume and routing flexibility with energy consideration model can be used by organizations then much debated issues such as overtime or night shift can be resolved. However this further requires empirical investigation.

\section{Conclusions}

Drawing broadly on flexible operations principles we have attempted to investigate the impact of volume and routing flexibility on energy sustainability. We have used case based research to analyze various scenarios using simulation techniques. Though we believe that our study offers multiple insights, we enumerate several limitations. Firstly, we have considered only volume and routing flexibility. However, if we had included the other four

flexibility dimensions then our findings could have been different. Secondly, our study findings are based on case based approach. Hence the theoretical findings where we have observed that volume and routing flexibility have no significant impacts on energy sustainability need to be further investigated using large sample size. Thirdly, other dimensions of sustainability such as social sustainability which we have not included in our present study can be explored in future. 


\section{Acknowledgments}

The authors are most grateful to anonymous reviewers for their constructive comments which helped to improve the presentation of the paper considerably.

\section{References}

Azadivar, F. \& Wang, J. (2000).Facility layout optimization using simulation and genetic algorithms. International Journal of Production Research, 38(17), 4369-4383.

Azzaro-Pantel, C., Bernal-Haro, L., Baudet, P., Domenech, S. \& Pibouleau, L. (1998). A two-stage methodology for short-term batch plant scheduling: discrete-event simulation and genetic algorithm. Computers \& Chemical Engineering, 22(10), 1461-1481.

Barad, M. \& Sapir, D. E. (2003).Flexibility in logistic systems-modeling and performance evaluation. International Journal of Production Economics, 85(2), 155-170.

Barnes, D. (2001). Research methods for the empirical investigation of the process of formation of operations strategy. International Journal of Operations \& Production Management, 21(8), 1076-1095.

Baud, R., 2008. The concept of sustainable development: aspects and their consequences from a social-philosophical perspective. In: YES Youth Encounter on Sustainability Summer Course material, 8-27 August 2008 Braunwald, Switzerland.

Boyd, A. G. 2005. Development of a performance-based industrial energy efficiency indicator for automobile assembly plants. Chicago: Argonne National Laboratory.

Browne, J., Dubois, D., Rathmill, S., Sethi, S.P., and Stecke, K.E., (1984). Classification of Flexible Manufacturing Systems. The FMS Magazine, 2 (1), 111-117. 
Bruzzone, A. A. G., Anghinolfi, D., Paolucci, M. \& Tonelli, F. (2012). Energyaware scheduling for improving manufacturing process sustainability: A mathematical model for flexible flow shops. CIRP Annals-Manufacturing Technology, 61(1), 459-462.

Chang, M. C. (2015). Room for improvement in low carbon economies of G7 and BRICS countries based on the analysis of energy efficiency and environmental Kuznets curves. Journal of Cleaner Production, 99, 140151.

Coughlan, P. and Coghlan, D., (2002). Action research for operations management. International Journal of Operations and Production Management, 22(2), 220-240.

Goldberg, D.E. (1989). Genetic Algorithms in Search, Optimization, and Machine Learning, Addison-Wesley, Reading.

Das, S. K. \& Abdel-Malek, L. (2003).Modeling the flexibility of order quantities and lead-times in supply chains. International Journal of Production Economics, 85(2), 171-181.

De Carvalho, A. N., Oliveira, F. \& Scavarda, L. F. (2015). Tactical capacity planning in a real-world ETO industry case: An action research. International Journal of Production Economics.167,187-203.

Dell, R. M. \& Rand, D. A. (2001).Energy storage-a key technology for global energy sustainability. Journal of Power Sources, 100(1), 2-17.

Dey, P. K., Bhattacharya, A. \& Ho, W. (2014). Strategic supplier performance evaluation: A case-based action research of a UK manufacturing organization. International Journal of Production Economics, 166,192-214.

Dubey, R., Gunasekaran, A. \& Chakrabarty, A. (2015). World-class sustainable manufacturing: framework and a performance measurement system. International Journal of Production Research, 53(17),5207-5223.

Dubey, R., Gunasekaran, A. \& Childe, S. J. (2015).The design of a responsive sustainable supply chain network under uncertainty. International Journal of Advanced Manufacturing Technology,80(1-4),427-445. 
Duclos, L. K., Vokurka, R. J. \& Lummus, R. R. (2003).A conceptual model of supply chain flexibility. Industrial Management \& Data Systems, 103(6), 446-456.

Duque Ciceri N., Garetti M., and Sperandio S., 2009. From product end-of-life sustainable considerations to design management. In Proceedings of APMS 2009, 21-23 September 2009 Bordeaux.

Fayezi, S., Zutshi, A. \& O'Loughlin, A. (2015). How Australian manufacturing firms perceive and understand the concepts of agility and flexibility in the supply chain. International Journal of Operations \& Production Management, 35(2), 246-281.

Garbie, I.H. (2013). DFSME: Design for sustainable manufacturing enterprises (an economic viewpoint). International Journal of Production Research, 51(2), 479-503.

Galitsky, C. (2008). Energy efficiency improvement and cost saving opportunities for the vehicle assembly industry: an energy star guide for energy and plant managers. Lawrence Berkeley National Laboratory.

Gimenez, C., Sierra, V., \&Rodon, J. (2012). Sustainable operations: Their impact on the triple bottom line. International Journal of Production Economics, 140(1), 149-159.

Graedel, T.E., Allwood, J., Birat, J.P., Buchert, M., Hagel"uken, C., Reck, B.K., Sonnemann, G. (2011). What do we know about metal recycling rates?. Journal of Industrial Ecology, 15(3), 355-366.

Gunasekaran, A. \& Spalanzani, A. (2012). Sustainability of manufacturing and services: Investigations for research and applications. International Journal of Production Economics, 140(1), 35-47.

Gunasekaran, A., Irani, Z. \& Papadopoulos, T. (2013). Modelling and analysis of sustainable operations management: certain investigations for research and applications. Journal of the Operational Research Society, 65(6), 806-823. 
Gupta, Y., Gupta, M., Kumar, A. and Sundaram, C., A genetic algorithm based approach to cell composition and layout design problems. International Journal of Production Research. 1996, 34, 447-482.

Hanna, M. D., Rocky Newman, W. \& Johnson, P. (2000). Linking operational and environmental improvement through employee involvement. International Journal of Operations \& Production Management, 20(2), 148165.

Herrmann, C., Thiede, S., Kara, S. \& Hesselbach, J. (2011). Energy oriented simulation of manufacturing systems-Concept and application. CIRP Annals-Manufacturing Technology, 60(1), 45-48.

Hoffman, A. J. (2001). From heresy to dogma: An institutional history of corporate environmentalism. Stanford University Press.

Industrial Development Report. (2013). Sustaining employment growth: The role of manufacturing and structural change. Vienna: United Nation Industrial Development Organization (UNIDO).

Johansson, B., Kacker, R., Kessel, R., McLean, C. \& Sriram, R. (2009, January).Utilizing combinatorial testing on discrete event simulation models for sustainable manufacturing. In ASME 2009 International Design Engineering Technical Conferences and Computers and Information in Engineering Conference (pp. 1095-1101). American Society of Mechanical Engineers.

Jamalnia, A. and Feili, A. (2013). A simulation testing and analysis of aggregate production planning strategies. Production Planning \& Control: The Management of Operations, 24(6), 423-448.

Jayal, A. D., Badurdeen, F., Dillon, O. W. \& Jawahir, I. S. (2010). Sustainable manufacturing: Modeling and optimization challenges at the product, process and system levels. CIRP Journal of Manufacturing Science and Technology, 2(3), 144-152. 
Joines, A.J., Culberth, T.C. and King, E.R. (1996) An integer-programming model employing genetic algorithms. Computers and Industrial Engineering, 28, 69-85.

Joseph, O. A. \& Sridharan, R. (2011).Evaluation of routing flexibility of a flexible manufacturing system using simulation modelling and analysis. The International Journal of Advanced Manufacturing Technology, 56(1-4), 273-289.

King, A. A. \& Lenox, M. J. (2001). Lean and green? An empirical examination of the relationship between lean production and environmental performance. Production and operations management, 10(3), 244-256.

Kleindorfer, P. R., Singhal, K. \& Wassenhove, L. N. (2005). Sustainable operations management. Production and Operations Management, 14(4), 482-492.

Kumar, P., Shankar, R. \& Yadav, S. S. (2008). Flexibility in global supply chain: modeling the enablers. Journal of Modelling in Management, 3(3), 277-297.

Laugen, B. T., Acur, N., Boer, H. \& Frick, J. (2005). Best manufacturing practices: what do the best-performing companies do?. International Journal of Operations \& Production Management, 25(2), 131-150.

Lins, I. D. \& Droguett, E. L. (2009).Multi-objective optimization of availability and cost in repairable systems design via genetic algorithms and discrete event simulation. Pesquisa Operacional, 29(1), 43-66.

Lins, I. D. \& Droguett, E. L. (2011).Redundancy allocation problems considering systems with imperfect repairs using multi-objective genetic algorithms and discrete event simulation. Simulation Modelling Practice and Theory, 19(1), 362-381.

Madaan, J. \& Mangla, S. (2015). Decision Modeling Approach for Eco-Driven Flexible Green Supply Chain. In Systemic Flexibility and Business Agility, 343-364. Springer India. 
Mahadevan, B., Pyke, D. F. \& Fleischmann, M. (2003).Periodic review, push inventory policies for remanufacturing. European Journal of Operational Research, 151(3), 536-551.

Mirzapour Al-e-hashem, S. M. J., Baboli, A. \& Sazvar, Z. (2013). A stochastic aggregate production planning model in a green supply chain: Considering flexible lead times, nonlinear purchase and shortage cost functions. European Journal of Operational Research, 230(1), 26-41.

Omar, M. A., Qilun, Z., Lujia, F., Ali, A. A., Lahjouji, D. \& Khraisheh, M. (2015). A hybrid simulation approach for predicting energy flows in production lines. International Journal of Sustainable Engineering, (ahead-of-print), $1-10$.

Onwubolu, G.C. and Mutingi, M., A genetic algorithm approach to cellular manufacturing systems. Computers Industrial Engineering, 2001, 39, $125-144$.

Oyarbide-Zubillaga, A., Goti, A. \& Sanchez, A. (2008).Preventive maintenance optimization of multi-equipment manufacturing systems by combining discrete event simulation and multi-objective evolutionary algorithms. Production Planning \& Control, 19(4), 342-355.

Pillai, V. M. \& Subbarao, K. (2008).A robust cellular manufacturing system design for dynamic part population using a genetic algorithm. International Journal of Production Research, 46(18), 51915210.

Rahimifard, S., Y. Seow, and T. Childs. 2010. "Minimizing Embodied Product Energy to Support Energy Efficient Manufacturing." CIRP Annals Manufacturing Technology 59 (1): 25-28.

Ramezanian, R., Rahmani, D. and Barzinpour, F., 2012. An aggregate production planning model for two phase production systems: Solving with genetic algorithm and Tabu search. Expert Systems with Applications, 39, 1256-1263. 
Reuter C, Foerstl K, Hartmann E, Blome C. (2010). Sustainable global supplier management. The role of dynamic capabilities in achieving competitive advantage. Journal of Supply Chain Management 46(2-3): 45-63.

Rosenbloom, S., 2001. Sustainability and automobility among the elderly: an international assessment. Transportation. 28, (4), 375-408.

Sethi, A.K. and Sethi, S.P. (1990). Flexibility in Manufacturing: A Survey. International Journal of Flexible Manufacturing Systems, 2 (4), 289328.

Severo, E. A., de Guimarães, J. C. F., Dorion, E. C. H. \& Nodari, C. H. (2015). Cleaner production, environmental sustainability and organizational performance: an empirical study in the Brazilian Metal-Mechanic industry. Journal of Cleaner Production, 96, 118-125.

Shojaeipour, S. (2015). Sustainable manufacturing process planning. The International Journal of Advanced Manufacturing Technology, 78(5-8), 1347-1360.

Singh, N. \& Rajamani, D. (2012). Cellular manufacturing systems: design, planning and control. Springer Science \& Business Media.

The World Bank, 2007.The Little Green Data Book 2007.The World Bank, Washington, DC.

Thiede, S., Herrmann, C., \& Kara, S. (2011). State of Research and an innovative Approach for simulating Energy Flows of Manufacturing Systems. In Globalized Solutions for Sustainability in Manufacturing (335340). Springer Berlin Heidelberg.

Voss, C., Tsikriktsis, N. \& Frohlich, M. (2002).Case research in operations management. International journal of operations \& production management, 22(2), 195-219.

Wiendahl, H. P. \& Dombrowski, U. (1987).Manufacturing routine analysis for the quantitative comparison of conventional and flexible manufacturing. The International Journal of Advanced Manufacturing Technology, 2(4), 41-62.

Winkler, H. (2009). How to improve supply chain flexibility using strategic supply chain networks. Logistics Research, 1(1), 15-25. 
Wohlgemuth, V., Page, B., \& Kreutzer, W. (2006). Combining discrete event simulation and material flow analysis in a component-based approach to industrial environmental protection. Environmental Modeling \& Software, 21(11), 1607-1617.

Yue, D. \& You, F. (2013). Sustainable scheduling of batch processes under economic and environmental criteria with MINLP models and algorithms. Computers \& Chemical Engineering, 54, 44-59. 